\title{
Structure and magnetic properties of powdered and compacted FeNi alloys
}

\author{
Denisa Olekšáková, ${ }^{*}$ Peter Kollár, ${ }^{* *}$ Ján Füzer $^{* *}$
}

\begin{abstract}
The crystalline ferromagnetic alloys are known as materials with excellent soft magnetic properties. These alloys have been intensive studied during last decades due to their mechanical and magnetic properties and they are challenge for scientists to extend research of these materials with the aim to broaden their technical applications. FeNi based alloys exhibit very good soft magnetic properties with near-to-zero magnetostriction. This property renders this material as a potential candidate for a differently of industrial applications.
\end{abstract}

K e y w ords: soft magnetic materials, coercivity, magnetization, powder, mechanical milling, mechanical alloying

\section{Introduction}

Modern electronic devices (such as digital telecommunication equipment, railway or automotive techniques, power supplies and others) supply of inductive components or magnetic cores with compact volumes and high universality in geometric shape and magnetic properties [1].

To realize such a power core materials are needed that exhibit an excellent combination of soft magnetic properties as: near-to-zero magnetostriction, low core loss, low coercivity, high permeability and saturation induction. For performance applications but also to achieve good frequency properties of coercivity and permeability and eddy current losses must be as low as possible [2].

For large scale industrial production the material must to exhibit the reliability to produce and to be easy to work of cores to electronic components. Moreover, the raw material should be easy to obtain and no expensive. The polycrystalline material $\mathrm{FeNi}$ is very suitable (excellent soft magnetic properties, cheap material etc) and very well known in low energy cores of transformers, anchors of electromotors and cores of magnetic recording heads. $\mathrm{FeNi}$ based alloy (called permalloy) system shows excellent soft magnetic properties and these alloys have been widely applied in the field of electronic devices and industry. The soft magnetic properties of permalloy are significantly dependent on Ni content: lower coercivity (alloy with about 80 at $\% \mathrm{Ni}$ ), higher saturation magnetic induction $(50$ at $\% \mathrm{Ni})$ and lower permeability, but higher electrical resistivity (about 35 at \% Ni) [3].

The shape in which are usually these materials prepared (conventional sheets, crystalline ribbon prepared by rapid solidification technology etc) is in many cases not suitable for industry applications. One of the ways to prepare bulk material (suitable for industrial applications) is the hot compaction of powder, which can be produced by the mechanical milling of thin ribbon, mixture of powders, sheets.

The mechanical ball milling technique has been successfully used to prepare many alloys in powder form, which are suitable for hot or cold compaction into a variety of shapes [4]. Mechanical milling is a non-equilibrium process for materials synthesis. This dry and high or low energy milling process has attracted considerable interest in recent years. This process was applied to a wide range of materials, leading to unstable and metastable phases under highly non-equilibrium conditions [5].

It was found that the addition of a small amount of molybdenum to FeNi alloy can have a strong effect on structural properties of resulting FeNiMo alloys (called supermalloy) leading to the improvement of soft magnetic properties with very high relative permeability and low eddy current losses [3].

The aim of this work was to investigate the structure and magnetic properties of powdered and compacted $\mathrm{Fe}_{19} \mathrm{Ni}_{81}$ (wt \%) and $\mathrm{Fe}_{16} \mathrm{Ni}_{79} \mathrm{Mo}_{5}$ (wt \%) alloys prepared by the mechanical milling and subsequently by a hot compaction of the powder.

\section{Experimental methods}

We have prepared two types of powder samples. The sample $\mathrm{Fe}_{19} \mathrm{Ni}_{81}$ was prepared by mechanical milling of microcrystalline ribbon $\mathrm{FeNi}$ ( 81 wt \% of $\mathrm{Ni}$ ) obtained by melt-spinning, which is suitable for milling. The sample $\mathrm{Fe}_{16} \mathrm{Ni}_{79} \mathrm{Mo}_{5}$ was prepared by the milling of the swarf of

\footnotetext{
* Faculty of Mechanical Engineering, Technical University in Košice, Letná 9, Košice 04200, Slovakia, ${ }^{* *}$ Institute of Physics, Faculty of Science, P. J. Šafárik, Park Angelinum 9, Košice 04154, Slovakia, denisa.oleksakova@tuke.sk
} 

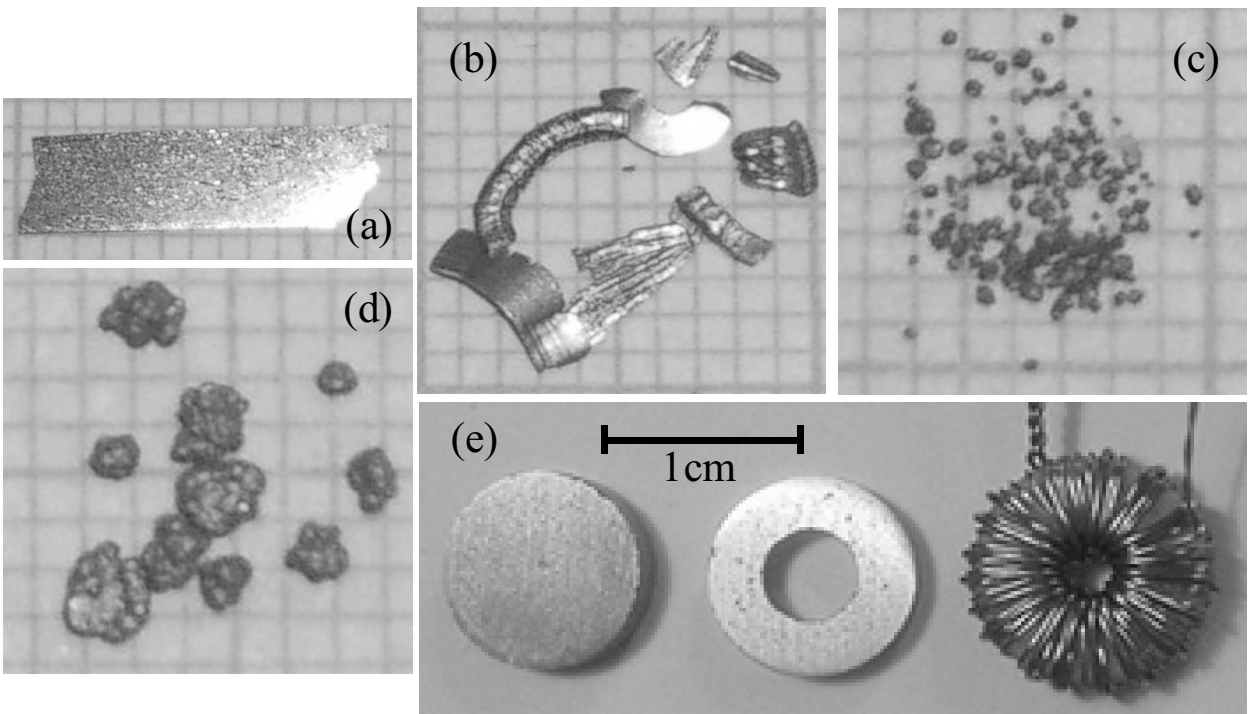

Fig. 1. (a) - ribbon $\mathrm{Fe}_{19} \mathrm{Ni}_{81}$, (b) - swarf $\mathrm{Fe}_{16} \mathrm{Ni}_{79} \mathrm{Mo}_{5}$, (c) - milled ribbon $\mathrm{Fe}_{19} \mathrm{Ni}_{81}$, (d) - milled swarf $\mathrm{Fe}_{16} \mathrm{Ni}_{79} \mathrm{Mo}_{5}$, and (e) bulk samples prepared by the compaction
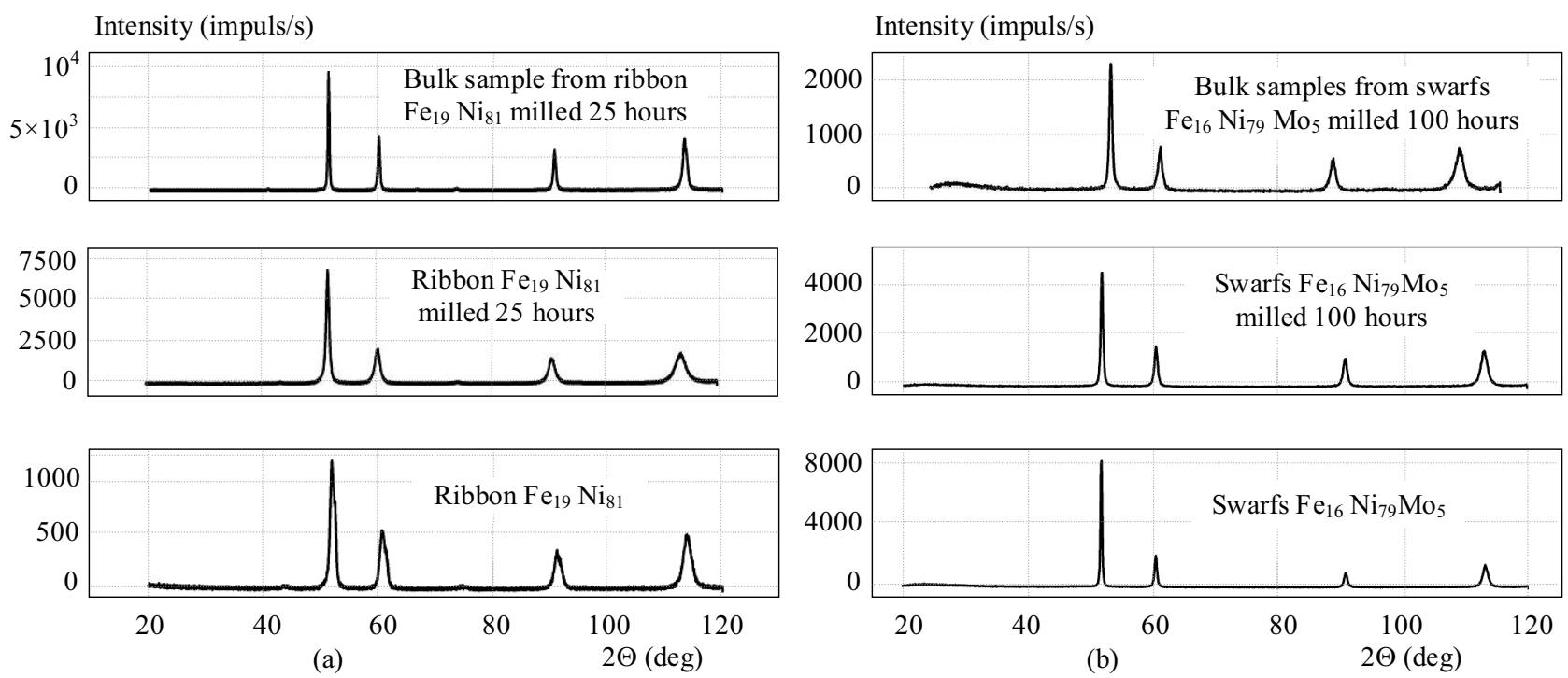

Fig. 2. XRD analysis for $\mathrm{Fe}_{19} \mathrm{Ni}_{81}$ and $\mathrm{Fe}_{16} \mathrm{Ni}_{79} \mathrm{Mo}_{5}$ powdered and compacted samples

FeNiMo ( 79 wt $\%$ of $\mathrm{Ni}, 16$ wt $\%$ of $\mathrm{Fe}$ ), which were prepared from an ingot by turning. We used swarf, because it was not possible to prepare ribbons with this chemical composition.

The mechanical milling was performed in a protective argon atmosphere in planetary ball mill (RETSCH PM4000) with ball-to-powder-ratio of 6:1 in hardened steel vials and with a speed of $180 \mathrm{rpm}$. The $\mathrm{Fe}_{16} \mathrm{Ni}_{79} \mathrm{Mo}_{5}$ sample was milled in a vial cooled in liquid nitrogen. The handling of the powder was performed in a glove box with a controlled atmosphere $\left(\mathrm{O}_{2}<1 \mathrm{ppm}, \mathrm{H}_{2} \mathrm{O}<1 \mathrm{ppm}\right)$ $[6,7]$.

The powder samples were consolidated at $800 \mathrm{MPa}$ for 5 minutes at $600{ }^{\circ} \mathrm{C}$ into discs with a diameter of 10 $\mathrm{mm}$ and a height of approximately $2.5 \mathrm{~mm}$. An axial hole with a diameter of $5 \mathrm{~mm}$ was drilled into the disc to produce ring samples. We have wound primary coil with 35 turns and secondary coil with 50 turns for AC and DC measurements.

The coercivity and magnetic moment of all powder samples were measured by vibratory sample magnetometer as a function of the milling time in magnetic field with maximum induction of $0.6 \mathrm{~T}$ at room temperature. The coercivity of bulk samples were measured by a Frster Koerzimat at room temperature.

The structure and morphology of the powder and bulk samples were characterised by the XRD investigations (Philips PW 1050 diffractometer with $\mathrm{Co}-\mathrm{K} \alpha$ radiation).

The DC hysteresis loops at maximum induction of $0.2 \mathrm{~T}$ were measured by a fluxmeter-based hysteresisgraph. The ac hysteresis loops were measured in the frequency range from $1 \mathrm{~Hz}$ to $50 \mathrm{~Hz}$. 


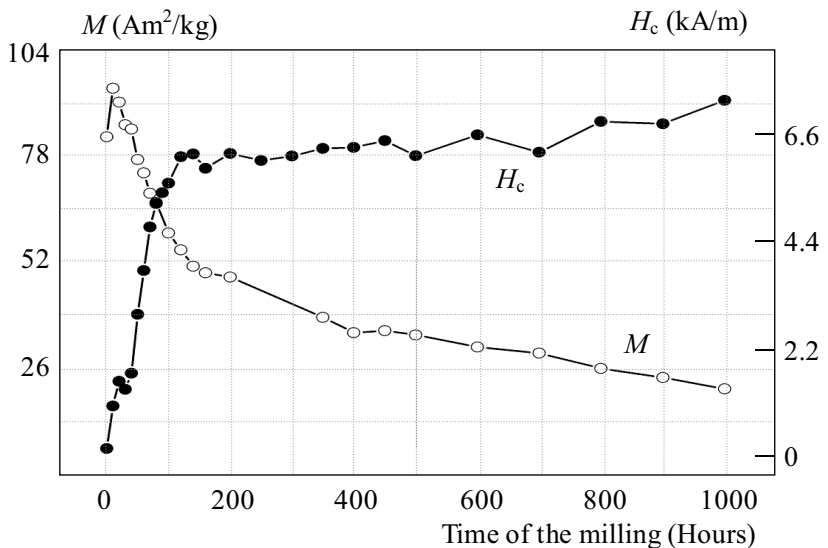

Fig. 3. The coercivity and the magnetization of sample $\mathrm{Fe}_{19} \mathrm{Ni}_{81}$

\section{Structure}

The structure and morphology of the powder and compacted samples $\mathrm{Fe}_{19} \mathrm{Ni}_{81}$ and $\mathrm{Fe}_{16} \mathrm{Ni}_{79} \mathrm{Mo}_{5}$ were investigated by X-ray diffraction.

XRD patterns of milled $\mathrm{Fe}_{19} \mathrm{Ni}_{81}$ ribbon and $\mathrm{Fe}_{19} \mathrm{Ni}_{81}$ compacted powder verifies our assumption of stability of the FeNi alloy during milling. There are present only peaks of $\mathrm{FeNi}_{3}$, Fig. 2 [7]. It means that no additional ferromagnetic FeNi phase is created during milling. The same results were founded for the $\mathrm{Fe}_{16} \mathrm{Ni}_{79} \mathrm{Mo}_{5}$ powder and $\mathrm{Fe}_{16} \mathrm{Ni}_{79} \mathrm{Mo}_{5}$ compacted samples (Fig. 2) and these results were reported in [8]. The XRD analysis revealed that the milling of the $\mathrm{Fe}_{19} \mathrm{Ni}_{81}$ microcrystalline ribbon and $\mathrm{Fe}_{16} \mathrm{Ni}_{79} \mathrm{Mo}_{5}$ swarf and the compaction of these powders have no significant influence on the structure of the material [6].

\section{Coercivity}

The behaviour of the coercivity and the magnetization for powder samples $\mathrm{Fe}_{19} \mathrm{Ni}_{81}$ and $\mathrm{Fe}_{16} \mathrm{Ni}_{79} \mathrm{Mo}_{5}$ depending on the milling time is noted in Fig. 3 and FDig, 4. We can see that magnetic moment monotonously decreases during all the milling time. It can be caused by the increasing of the volume fraction of fine particles exhibiting such size, in which the domain structure is not formed and external magnetic field $(0.6 \mathrm{~T})$ is not enough for the producing of the saturation state by the rotation of the magnetization vector. The next reason may be the formation of such small particles, which exhibit superparamagnetic behaviour with blocking temperature in above mentioned external field below room temperature.

The coercivity of the powder sample increases with milling time and we assume that displacement of the domain walls becomes less and less important magnetization process with milling time and the rotation of magnetization vector becomes more dominant. The magnetization process of the powder material is realized more or less separately for each powder element $[5,6]$.

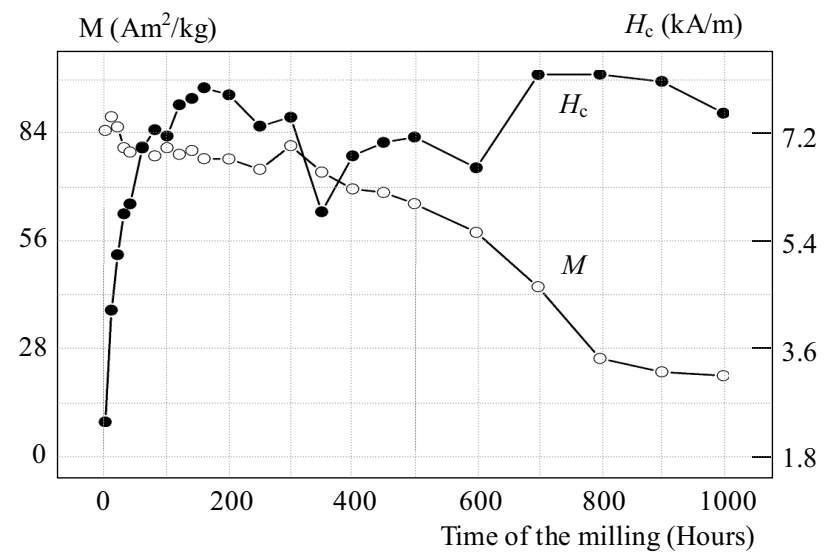

Fig. 4. The coercivity and the magnetization of sample $\mathrm{Fe}_{16} \mathrm{Ni}_{79} \mathrm{Mo}_{5}$

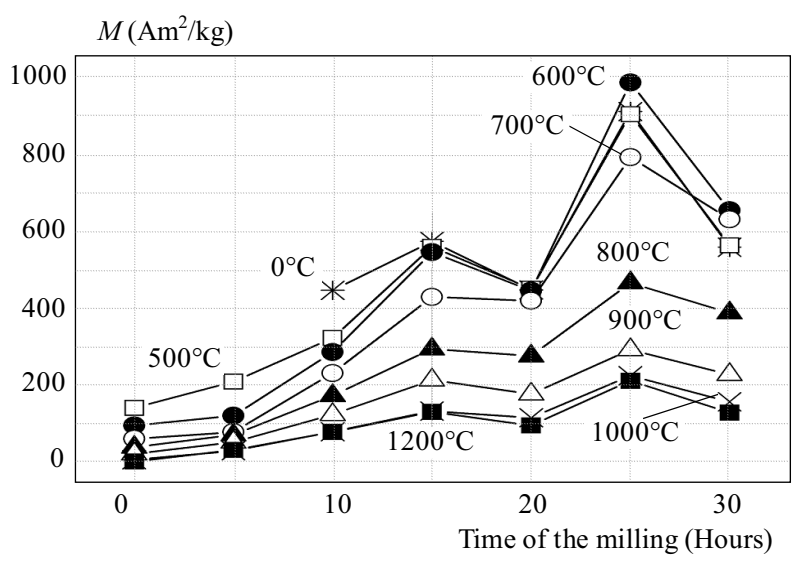

Fig. 5. The coercivity of bulk samples prepared by the compaction of powder $\mathrm{Fe}_{19} \mathrm{Ni}_{81}$ milled from 0 to 30 hours and compacted at the range $0{ }^{\circ} \mathrm{C}-1200{ }^{\circ} \mathrm{C}$

The coercivity of the bulk material before heat treatment is lower than that for powder and that is why we can assume that the "magnetic contact" is restored after compaction. The annealing at higher temperatures causes relaxation of residual stresses introduced during milling and compaction and improves contact between powder particles, causing lowering of the coercivity. The lowest coercivity $11 \mathrm{~A} / \mathrm{m}$ was achieved for $\mathrm{Fe}_{19} \mathrm{Ni}_{81}$ sample prepared by compaction $\left(600^{\circ} \mathrm{C}\right)$ of broken ribbon, annealed at $1200^{\circ} \mathrm{C}$ [6], and it is comparable with that for material prepared by convention way in the form of thin sheet [9], Fig. 5.

In the case of $\mathrm{Fe}_{16} \mathrm{Ni}_{79} \mathrm{Mo}_{5}$ samples the coercivity decreases with increasing annealing temperature, reaching a minimum value of $11.2 \mathrm{~A} / \mathrm{m}$ ( swarf $^{\mathrm{Fe}_{16}} \mathrm{Ni}_{79} \mathrm{Mo}_{5}$ milled 1 hour and compacted at $600{ }^{\circ} \mathrm{C}$ and annealed at $\left.1100{ }^{\circ} \mathrm{C}\right)[4,10]$.

In order to prepare ring-shaped samples more suitable for AC and DC measurements, the cylinders of bulk samples were drilled using spark plasma erosion (the diameter of the hole is $5 \mathrm{~mm}$ ). The coercive field increases with milling time for both types of samples as can be followed from DC hysteresis loops measured at 0.2 T, Fig. 6 . 

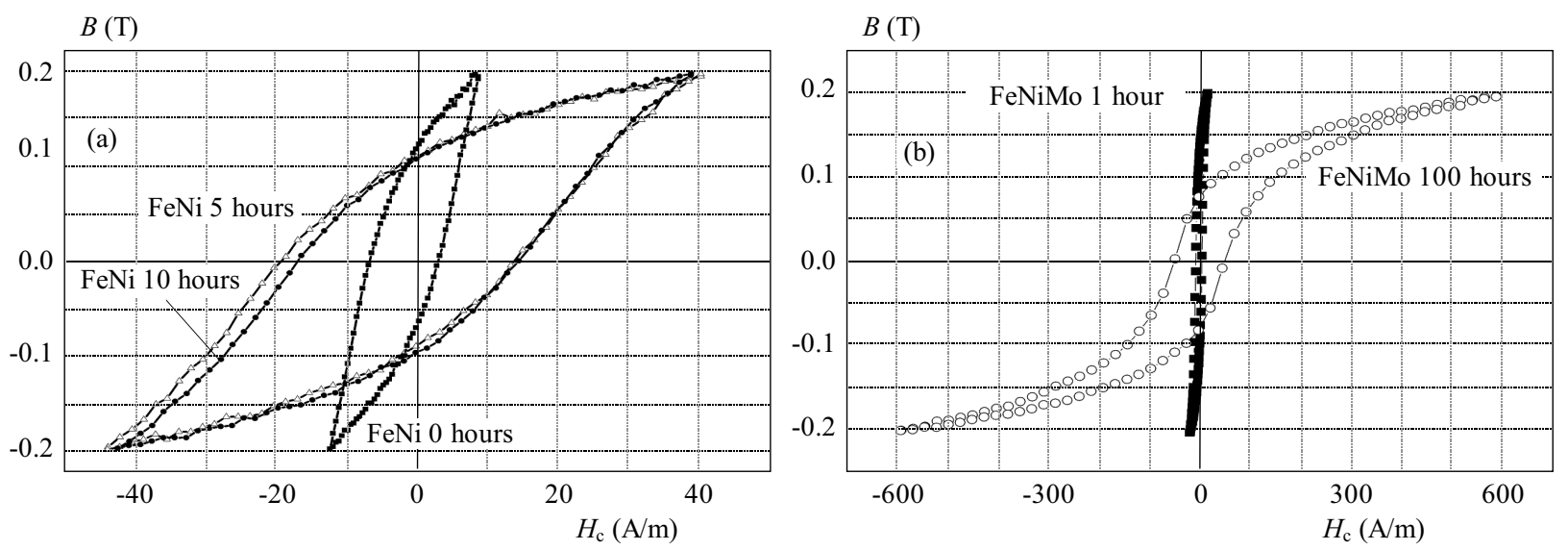

Fig. 6. The DC hysteresis loops of bulk samples $\mathrm{Fe}_{19} \mathrm{Ni}_{81}$ and $\mathrm{Fe}_{16} \mathrm{Ni}_{79} \mathrm{Mo}_{5}$ prepared by the compaction of powder miler the different time

\section{Conclusion}

The soft magnetic properties of the $\mathrm{Fe}_{19} \mathrm{Ni}_{81}$ and $\mathrm{Fe}_{16} \mathrm{Ni}_{79} \mathrm{Mo}_{5}$ alloys have been investigated. From the above study, we conclude that the magnetic properties of the permalloy and supermalloy show strong dependence to their initial master powder and annealing conditions. The bulk sample $\mathrm{Fe}_{16} \mathrm{Ni}_{79} \mathrm{Mo}_{5}$ is found to show better soft magnetic properties overt he $\mathrm{Fe}_{19} \mathrm{Ni}_{81}$ bulk sample as a function of different process parameters. We have prepared bulk samples in the form of the small cylinders with coercivity down to approximately $11 \mathrm{~A} / \mathrm{m}$. The discussed alloys show very good soft magnetic properties that can be tailored to the need of certain requirements by adjusting the chemical composition, the processing routes such as compaction, and heat treatment conditions. They have more degrees of freedom for tailoring their magnetic properties due to their flexibility in composition, shape and dimensions.

\section{Acknowledgements}

This work was supported by the Science and Technology Assistance Agency under the contract No. APVV-150115 and by the Scientific Grant Agency of the Ministry of Education of Slovak Republic and the Slovak Academy of Science VEGA 1/0330/15, VEGA 1/0377/16.

\section{REFERENCES}

[1] G. Herzer, "Modern soft magnets, Amorphous and nanocrystalline materials", Acta Materialia, vol. 61 (2013), pp. 718-734.

[2] J. Petzold, "Applications of nanocrystalline softmagnetic materials for modern electronic devices", Scripta Materialia, vol. 48 (2003), pp. 895-901.

[3] J. M. D. Coey, Magnetism and Magnetic Materials, Camridge University Press (2014).

[4] J. Füzer, P. Kollár, D. Olekšáková, and S. Roth, "AC magnetic properties of the bulk $\mathrm{Fe}-\mathrm{Ni}$ and $\mathrm{Fe}-\mathrm{Ni}$-Mo soft magnetic alloys prepared by warm compaction", J. Alloys and Compd., vol. 483 (2009), pp. 557.

[5] C. Suryanarayana, "Mechanical alloying and milling", Progress in Materials Science, vol. 46 (2001), pp. 1.

[6] D. Olekšáková, P. Kollár, J. Füzer, M. Kusý, S. Roth and K. Polanski, "The influence of mechanical milling on structure and soft magnetic properties of $\mathrm{NiFe}$ and NiFeMo alloys", Journal of Magnetism and Magnetic Materials, vol. 316(2007), pp. e838-e841.

[7] D. Olekšáková, S. Roth, P. Kollár and J. Füzer, "Soft magnetic properties of NiFe compacted powder alloys", Journal of Magnetism and Magnetic Materials, vol. 304 (2006), pp. e730-e732.

[8] D. Olekšáková, J. Füzer and P. Kollár, "Isobaric Thermal Expansion and Isothermal Compression of Powdered NiFe Based Alloys Studied by In-Situ EDXRD", Acta Physica Polonica A 126 (2014), pp. 128-130.

[9] A. H. Morrish, The physical Principles of Magnetism, E. Krieger Publ. Co, Huntington (1980).

[10] J. Füzer, P. Kollŕ, D. Olekšáková and S. Roth, "Soft Magnetic Properties in Bulk Permalloy Alloys Fabricated by a Warm Consolidation", Acta Physica Polonica A vol.113(2008), pp. 59-61.

Received 10 April 2016

Denisa Olekšáková received $\mathrm{PhD}$ degree in Physics of Condensed Matter and Acoustics at the P. J. Šafárik University in Košice in 2007. At present, she works as a lecturer at the Department of Applied Mathematics and Informatics of the Faculty of Mechanical Engineering of Technical University in Košice. Her research interest is the investigation of the structure and magnetic properties of soft magnetic materials.

Peter Kollár is Professor at P. J. Šafárik University in Košice, Faculty of Sciences, Department of Physics. His research interest is the investigation of magnetization and relaxation processes in magnetic particles and soft magnetic composites.

Ján Füzer is Associate Professor at P. J. Šafárik University in Košice, Faculty of Sciences, Department of Physics. His research interest is the investigation of the structure and magnetic properties of soft magnetic composites. 